\title{
Education as a Protective Factor Moderating the Effect of Depression on Memory Impairment in Elderly Women
}

\author{
Jiyoun Lee ${ }^{1 *}$, Heyeon Park ${ }^{1,2^{*}}$, and Jeanyung Chey ${ }^{1 凶}$ \\ ${ }^{1}$ Department of Psychology, Seoul National University, Seoul, Republic of Korea \\ ${ }^{2}$ Department of Public Health Medical Services, Seoul National University Bundang Hospital, Seongnam, Republic of Korea
}

Objective The cognitive reserve theory explicates individual differences observed in the clinical manifestation of dementia despite similar brain pathology. Education, a popular proxy of the cognitive reserve, has been shown to have protective effects delaying the onset of clinical symptoms including memory. This study was conducted to test whether education can moderate the negative effect of depressive mood on memory performance in elderly women residing in the community.

Methods 29 elderly "unschooled" female (less than 6 years of formal education) and 49 "schooled" female (6 or more years) people were compared with regard to association between depressive mood and verbal memory functioning, which were measured by the Geriatric Depression Scale and the Elderly Verbal Learning Test, respectively.

Results The results showed that completing or receiving more than primary school education significantly reduced the negative association between depressive mood and memory performance. Participants who did not complete primary schooling showed a decline in memory test scores depending on the level of depressive mood; whereas participants who have completed or received more than primary education displayed relatively stable memory function despite varying level of depressive mood.

Conclusion Our findings imply that education in early life may have protective effects against memory impairment related to elderly depression.

Psychiatry Investig 2018;15(1):70-77

Key Words Cognitive aging, Cognitive reserve, Dementia, GDS, EVLT.

\section{INTRODUCTION}

Increased lifespan and the corresponding expansion of the elderly population above the age of 65 have led to the most challenging public health issues in developed and developing countries including South Korea. In response to the rapidly changing demographics, there has been an exponential growth in the number of initiatives and interventions designed to promote successful aging. ${ }^{1}$ Successful aging refers to physical, mental, and social well-being in older age. Researchers aim to define what differentiates successful aging from pathological aging in order to design effective strategies and treatments that can potentially protect the health and well-being of the el-

Received: February 14, 2017 Revised: June 25, 2017

Accepted: August 31, 2017 Available online: November 7, 2017

$\triangle$ Correspondence: Jeanyung Chey, $\mathrm{PhD}$

Department of Psychology, Seoul National University, 1 Gwanak-ro, Gwanakgu, Seoul 08826, Republic of Korea

Tel: +82-2-880-6432, Fax: +82-2-877-6428, E-mail: jychey@snu.ac.kr

*These authors contributed equally to this work.

@ This is an Open Access article distributed under the terms of the Creative Commons Attribution Non-Commercial License (http://creativecommons.org/licenses/by$\mathrm{nc} / 4.0$ ) which permits unrestricted non-commercial use, distribution, and reproduction in any medium, provided the original work is properly cited. derly people.

With the exception of a few cognitive functions, various mental faculties decline with aging. Memory has been depicted as one of the most vulnerable psychological function associated with aging. The ability to encode new memories of events or facts and working memory have been shown to decline in aging population both in cross-sectional and longitudinal studies. ${ }^{2}$ Older adults demonstrate deficits, relative to young adults, in episodic memory or more accurately in explicit tests of memory that require the conscious retrieval of previously experienced events. ${ }^{3,4}$

Late-life depression is another increasingly significant public health problem in countries with rapidly population aging, notably South Korea showing the fastest rate of population aging. Park and colleagues estimated the prevalence rates for possible and probable depression in Korean elders as 10.1\% and $17.8 \%$, respectively. ${ }^{5}$ Another study estimated the prevalence of major depressive disorder among elderly Koreans as $5.37 \%$, which is higher than those observed in most Western countries and other Asian countries. ${ }^{6}$ However, they claim that this may reflect only a small proportion of the actual prob- 
lem, since a considerable amount of the elderly people with clinically significant depressive symptoms do not meet the rigorous diagnostic criteria of the Diagnostic and Statistical Manual of Mental Disorders, 5th edition ${ }^{7}$ for major depressive disorder. Although depression is one of the most common and treatable mental illnesses, late-life depression can oftentimes go unrecognized and untreated due to its sub-threshold features and complicated etiologies. Consequences of inadequately treated late-life depression are substantial, even when it is at a sub-threshold level. It has been suggested that this subthreshold late-life depression may be just as disabling and detrimental to the well-being of an elderly individual as major depressive disorder. ${ }^{8}$

It has long been observed that depression is associated with memory impairment. Cohen and colleagues claimed that depressed patients perform comparatively poorly on memory tasks, ${ }^{9}$ while Sternberg and Jarvik have discovered that depressed patients significantly improved their memory performance after treatment with antidepressants or other therapies, ${ }^{10}$ suggesting that there may be underlying biochemical mechanisms that relate depression and memory impairment. Indeed, more recent evidence from longitudinal studies showed that late-life depression was associated with a 2 to 5 -fold increased risk of dementia, to which memory impairment contributes significantly. ${ }^{11-14}$ Another 7-year longitudinal study found that even one additional depressive symptom in older adults increased the risk of dementia by 20 percent, ${ }^{15}$ suggesting that the severity of late-life depression may influence the risk of dementia.

Depression, however, has not been found to have detrimental effects at follow-up in other studies. ${ }^{16,17}$ Discrepancy in the results and the amount of risk depressive mood may pose on dementia and memory decline could be explained by variations in sample size, measures used to assess depressive mood, as well as the frequency and severity of depression. Another possibility is that there are individual differences in the effects of depression on memory decline. According to the cognitive reserve hypothesis, some people are able to tolerate higher levels of brain pathology before displaying clinical symptoms than others. The hypothesis asserts that there is an ability to optimize performance through differential recruitment of brain networks or alternative cognitive strategies. ${ }^{18-20}$ In other words, cognitive reserve allows for more neural efficiency, capacity, and flexible strategy use in the face of aging and pathology. Assuming this hypothesis is true, individuals with higher cognitive reserve will have a delayed onset of cognitive decline, and clinical diagnostic criteria for dementia will be reached later, when the pathology is more severe. The concept of cognitive reserve offers an explanation to why many studies have demonstrated that individuals with higher levels of intelligence and educational and occupational attainment are able to sustain greater brain pathology before demonstrating functional deficit.

One of the most well-established proxy measures of cognitive reserve is educational attainment, which is thought to reflect more effective use of brain networks or cognitive capacity. ${ }^{21,22}$ In line with the hypothesis of cognitive reserve, many studies in both North America and Europe have suggested that educational attainment is associated with better cognitive performance and reduced risk for cognitive impairment and dementia in late-life. ${ }^{23-28}$ One longitudinal study examined memory test data that was collected at regular intervals from healthy elderly individuals who were followed up until they became demented. It was found that higher education delayed the onset of accelerated cognitive decline, and that the rate of memory decline after its onset was more rapid in those with higher education due to increased pathology burden. ${ }^{29}$

Similar findings have been reported with respect to memory decline and cognitive decline in normal aging populations, indicating that the evidence is not only limited to reducing the risk of dementia. ${ }^{30-34}$ Studies have shown that education attenuates cognitive decline among non-demented older adults. ${ }^{32,35-39}$ The results from these studies support an active cognitive reserve hypothesis in which education promotes more efficient cognitive processing and use of brain networks, which ultimately results in slowing the process of age-related cognitive decline. $^{40}$

The aim of this study was to investigate whether education, a proxy of cognitive reserve, moderates the negative effect of depressive mood on memory impairment and thus, acts as a protective factor against cognitive decline. A positive finding would have important implications in terms of delaying memory impairment in the elderly population, especially in South Korea where the society is quickly aging and the rate of latelife depression is high. The hypothesis was that 1) depressive mood would result in lower verbal memory performance in normal elderly people and 2) elderly people with moderate education would show significantly smaller decline in memory performance associated with depressive mood, whereas those with low educational attainment would display significant decline in memory associated with increasing depressive mood level. In other words, education was expected to serve as a moderator by dampening the negative effect that depressive mood has on memory.

\section{METHODS}

\section{Participants}

Female elderly individuals were recruited from eight local senior welfare centers in Seoul, South Korea. Seventy eight 
out of the 101 participants, determined as normal by clinicians, were included in the final analyses. They were between the ages of 65 and 87 years (mean age $=74.05, \mathrm{SD}=5.61$ ), had no history of a neurological disorder, major psychiatric disorder, neurosurgical history (such as head trauma or brain surgery), no history of diabetes or hypertension that was difficult to regulate with medication, and no hearing nor vision problem that could cause difficulty in performing cognitive tasks. Also, their cognitive function assessment (Korean Dementia Rating Scale-2) ${ }^{41}$ results were within the normal range. Within this sample, we classified participants having less than 6 years of education as the "unschooled" group $(n=29)$, while participants having 6 or more years of education were categorized as the "schooled" group $(n=49)$. The categorization was based on the fact that primary school education was observed to have the most significant effect on basic cognitive functioning, ${ }^{42}$ possibly because it involves acquiring basic reading and arithmetic skills that lays the foundation for further learning. Further, obligatory education for elderly Koreans was the completion of 6 years of primary school. Demographic data on the participants are presented in Table 1.

All participants provided written informed consent, and the study was approved by the Seoul National University Institutional Review Board (IRB No. 1402/002-016).

\section{Neuropsychological assessments}

\section{Depressive mood}

The Geriatric Depression Scale (GDS) ${ }^{43}$ was used to assess the degree of depressive mood of the participants. The GDS is one of the most popular self-report scale of depression for the elderly individuals. Researchers and clinicians have often used this scale for assessing sub-threshold depressive symp- toms as well. The 30 items included in the GDS are based on characteristics of depression in the elderly. ${ }^{44}$ The GDS's relevance is also seen in its capacity for measuring the same overall construct of depression as the most universal and widely studied scale for depression in adults, the BDI. Also, the simplicity of the response procedure and brief average length enhance understanding, diminish anxiety generated by administration of a psychological test, and produce a high completion rate. $^{45}$

\section{Perceived stress}

We assessed the level of perceived stress in order to control its effect on the relationship between depressive mood and memory in normal elderly participants. We utilized the Korean version of the Perceived Stress Scale ${ }^{46}$ which was modified for Korean elderly people. ${ }^{47}$ The PSS was designed to measure the degree to which respondents found their life situations unpredictable, uncontrollable, and overloading. The scale includes 10 direct queries asking about incidents that brought upon states of being upset, nervous, stressed or irritated. Perceived stressfulness of each item of the scale was rated from 0 to 5 instead of from 0 to 4 in the original version. Scores ranged from 0 to 50 , with higher scores indicating more perceived stress.

\section{Cognitive tests}

The Korean Dementia Rating Scale-2 (K-DRS-2) was administered to screen for dementia. The DRS-2 is an assessment tool that examines an individual's overall level of cognitive functioning and yields five subscale scores. The five subscales provide additional information on specific abilities, including Attention, Initiation/Perseveration, Construction, Conceptualization, and Memory. Within each subscale, the

Table 1. Age, education, the subjective socioeconomic status, the GDS, the PSS, and the EVLT scores by group: two-sample t-test and cross tabulation

\begin{tabular}{|c|c|c|c|c|}
\hline & $\begin{array}{c}\text { Unschooled } \\
\mathrm{M} \pm \mathrm{SD} \text { or } \mathrm{N}(\%)\end{array}$ & $\begin{array}{c}\text { Schooled } \\
\mathrm{M} \pm \mathrm{SD} \text { or } \mathrm{N}(\%)\end{array}$ & $\mathrm{T}$ or $\chi^{2}$ & $\mathrm{p}$ \\
\hline Age & $76.83 \pm 4.91$ & $72.41 \pm 5.39$ & 3.614 & 0.001 \\
\hline Years of education & $2.45 \pm 1.90$ & $8.71 \pm 2.81$ & 11.731 & $<0.001$ \\
\hline \multicolumn{5}{|c|}{ Subjective socioeconomic status } \\
\hline Lower-class & $12(41.38)$ & $15(30.61)$ & 1.495 & 0.683 \\
\hline Lower-middle class & $11(37.93)$ & $20(40.82)$ & & \\
\hline Upper-middle class & $6(20.69)$ & $13(26.53)$ & & \\
\hline Upper class & $0(0)$ & $1(2.04)$ & & \\
\hline PSS & $13.72 \pm 8.20$ & $8.87 \pm 1.27$ & 0.884 & 0.380 \\
\hline GDS & $10.24 \pm 4.41$ & $10.18 \pm 7.31$ & 0.044 & 0.965 \\
\hline EVLT Immediate Recall & $5.83 \pm 1.54$ & $5.76 \pm 1.75$ & 0.185 & 0.854 \\
\hline EVLT Delayed Recall & $6.03 \pm 1.57$ & $5.88 \pm 1.50$ & 0.440 & 0.661 \\
\hline EVLT Recognition & $26.41 \pm 2.51$ & $26.88 \pm 2.84$ & 0.726 & 0.470 \\
\hline
\end{tabular}

GDS: geriatric depression scale, PSS: perceived stress scale, EVLT: Elderly Verbal Learning Test 
most difficult tasks are presented first. If the first one or two tasks in a subscale are performed well, subsequent tasks in the subscale are credited with a correct performance and the examiner proceeds to the next subscale, which allows for a significant testing efficiency. The K-DRS-2 is the adapted and standardized version of the DRS-2. ${ }^{41}$ Age- and education-corrected norms are provided for all K-DRS-2 subscales and total score.

Elderly Verbal Learning Test (EVLT $)^{48}$ was used to measure verbal memory. It is a word list learning task developed for elderly adults with low to moderate level of education. It provides measurement of verbal learning and memory, by using the paradigm of the California Verbal Learning Test. ${ }^{49,50}$ The EVLT uses a list consisting of 9 words from three categories presented over five trials. Throughout the five trials, the subjects are told to repeat as many of the words as they can remember from the list. This allows for the calculation of immediate recall memory. After the introduction of the target list, an interference list of 9 different words is presented and the subjects are told to repeat this new list. This is followed by the short-delay recall of the target list and then long-delay recall after 15 to 30 minutes. A recognition trial is also administered at the end of the test, in which the subjects are given 30 words one at a time, and are asked to indicate whether each word was a part of the original list. Thus, the EVLT provides information about acquisition, recall, retention, and retrieval of verbal information.

\section{Procedure}

All subjects participated in an approximately 50-minute one-on-one interview surveying the demographic, socio- economic, and social activity background, and were screened for non-demented healthy elderly woman using inclusionary criteria. The participants were then scheduled to partake in the second phase of the study approximately 5.97 months later (SD: 1.78 , range: 4 to 9 months) to evaluate cognitive functions. The subjects participated individually in an approximately 70-minute test session in a quiet environment. The order of the cognitive tasks that were administered was invariant across all participants. The current study used the depression scale data that was administered in the first data collection phase, while data of cognitive tests were from the second phase.

Neuropsychological tests and interviews were administered by clinical trainees and clinical psychology specialists. Three clinical psychologists participated in case conferences that determined whether participants met the inclusionary criteria. Hearing difficulty or vision problems were determined at the beginning of each interview, and participants were encouraged to use their glasses and/or hearing aids. Those who had significant difficulty hearing our instructions or seeing the stimuli with the available aids were also excluded from the study.

\section{Analysis}

The collected data were analyzed in two steps using the IBM SPSS Statistics 21 (IBM Corp., Armonk, NY, USA). First, we conducted a regression analysis using age, years of education, PSS total scores, and GDS total scores as independent variables, and EVLT scores as dependent variables in the entire sample of 78 elderly participants. It was intended to explore whether or not the predictability of depression on the memory function in all participants is significant after controlling for age, years of education, and perceived stress. Secondly, we

Table 2. Multiple regression models on the EVLT scores $(\mathrm{N}=78)$

\begin{tabular}{|c|c|c|c|c|c|c|c|}
\hline Dependent variable & Regressors & $\mathrm{B}$ & Std. error & $\beta$ & $\mathrm{T}$ & $\mathrm{p}$ & $\mathrm{R}^{2}$ \\
\hline \multirow{5}{*}{ EVLT Immediate Recall } & Constant & 9.11 & 2.76 & & 3.30 & 0.001 & 0.06 \\
\hline & Age (years) & -0.04 & 0.04 & -0.12 & -1.01 & 0.318 & \\
\hline & Education (years) & 0.00 & 0.05 & 0.01 & 0.06 & 0.950 & \\
\hline & PSS & -0.03 & 0.02 & -0.13 & -1.02 & 0.313 & \\
\hline & GDS & -0.04 & 0.03 & -0.14 & -1.07 & 0.290 & \\
\hline \multirow[t]{5}{*}{ EVLT Delayed Recall } & Constant & 9.29 & 2.43 & & 3.82 & $<0.001$ & 0.12 \\
\hline & Age (years) & -0.04 & 0.03 & -0.14 & -1.24 & 0.221 & \\
\hline & Education (years) & 0.03 & 0.04 & 0.07 & 0.62 & 0.537 & \\
\hline & PSS & 0.00 & 0.02 & 0.02 & 0.17 & 0.872 & \\
\hline & GDS & -0.07 & 0.03 & -0.31 & -2.52 & 0.014 & \\
\hline \multirow[t]{5}{*}{ EVLT Recognition } & Constant & 35.44 & 4.13 & & 8.59 & $<0.001$ & 0.21 \\
\hline & Age (years) & -0.10 & 0.05 & -0.20 & -1.83 & 0.071 & \\
\hline & Education (years) & 0.07 & 0.08 & 0.10 & 0.87 & 0.39 & \\
\hline & PSS & -0.04 & 0.04 & -0.13 & -1.14 & 0.257 & \\
\hline & GDS & -0.14 & 0.05 & -0.32 & -2.78 & 0.007 & \\
\hline
\end{tabular}

EVLT: Elderly Verbal Learning Test, B: regression coefficients, Std. error: standard error of regression coefficient, $\beta$ : standardized regression coefficient, PSS: perceived stress scale, GDS: geriatric depression scale 
divided participants into "unschooled" and "schooled" education groups. We then applied a similar regression model on the data of each group to investigate whether the influence of depression on memory function in elderly people is different depending on the level of education.

\section{RESULTS}

Initial regression analysis of the entire sample showed that the GDS total score significantly predicted the EVLT Delayed Recall score ( $p=0.014)$ and Recognition score $(p=0.007)$ even after controlling the effects of age, education, and perceived stress (Table 2). The effect of the GDS total score on the EVLT immediate recall was insignificant $(\mathrm{p}=0.290)$.

Next, in order to investigate whether the relationship between depressive mood and memory functioning in normal elderly people is different depending on educational attainment, we divided participants into two groups and compared them: the "unschooled" group (years of education $<6$ ) versus the "schooled" group (years of education $\geq 6$ ). A two-sample $\mathrm{t}$-test showed that differences in the mean and the variance in depression, perceived stress and verbal memory functioning were not significant between the two education groups.
The subjective socioeconomic status was not different significantly between the two groups (Table 1). As expected, depressive mood was more related with EVLT scores in the "unschooled" elderly group than with those in the "schooled" elderly group (Figure 1). More specifically, the correlation coefficients between the GDS total score and the EVLT scores were significant among "unschooled" individuals (Immediate Recall: $r=-0.38, p=0.040$; Delayed Recall: $r=-0.50, p=0.006$; Recognition: $r=-0.45, \mathrm{p}=0.014)$, while among "schooled" individuals, the GDS total score had a significant correlation with only the EVLT Recognition score (Immediate recall: $r=$ $-0.13, \mathrm{p}=0.373$; Delayed Recall: $\mathrm{r}=-0.24, \mathrm{p}=0.099$; Recognition: $\mathrm{r}=-0.36, \mathrm{p}=0.010)$. In order to further investigate whether the effect of depressive mood on memory is dependent on educational attainment, regression analyses were performed for each group (Table 3, 4, and 5). The regression model placed EVLT scores as the dependent variable, while age and the PSS and GDS scores were used as regressors. Within the "unschooled" group, the GDS total score significantly predicted Immediate Recall, Delayed Recall, and Recognition scores on the EVLT ( $\mathrm{p}=0.026,0.001,0.017$, respectively), even after controlling the effects of age and perceived stress. On the other hand, in the "schooled" group, it did not predict EVLT scores
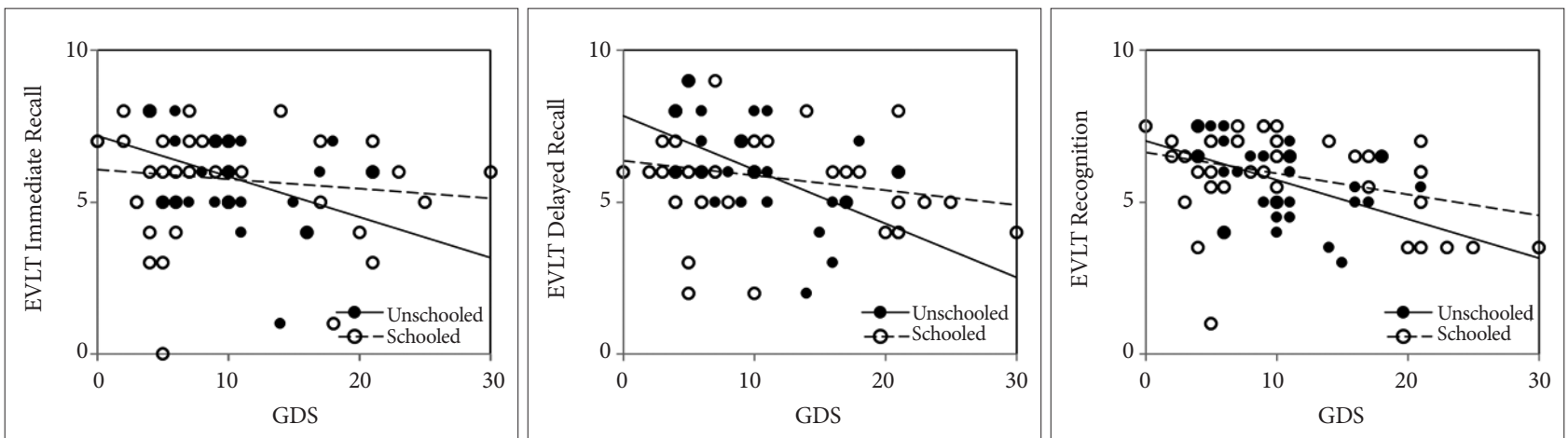

Figure 1. Association between depression and memory depending on educational attainment. EVLT: Elderly Verbal Learning Test, GDS: Geriatric Depresion Scale.

Table 3. Group differences in multiple regression model on the EVLT Immediate Recall

\begin{tabular}{|c|c|c|c|c|c|c|}
\hline Regressors & B & Std. error & $\beta$ & $\mathrm{T}$ & $\mathrm{p}$ & $\mathrm{R}^{2}$ \\
\hline Unschooled (N=29) & & & & & & 0.27 \\
\hline Constant & 13.16 & 4.23 & & 3.11 & 0.005 & \\
\hline Age (years) & -0.08 & 0.05 & -0.26 & -0.15 & 0.147 & \\
\hline PSS & 0.04 & 0.04 & 0.21 & 1.10 & 0.283 & \\
\hline GDS & -0.16 & 0.07 & -0.45 & -2.37 & 0.026 & \\
\hline Schooled (N=49) & & & & & & 0.09 \\
\hline Constant & 7.19 & 3.41 & & 2.11 & 0.040 & \\
\hline Age (years) & -0.01 & 0.05 & -0.02 & -0.16 & 0.870 & \\
\hline PSS & -0.06 & 0.03 & -0.30 & -1.83 & 0.070 & \\
\hline GDS & 0.00 & 0.04 & 0.00 & 0.03 & 0.980 & \\
\hline
\end{tabular}

EVLT: Elderly Verbal Learning Test, B: regression coefficients, Std. error: standard error of regression coefficient, $\beta$ : standardized regression coefficient, PSS: perceived stress scale, GDS: geriatric depression scale 
Table 4. Group differences in multiple regression model on the EVLT Delayed Recall

\begin{tabular}{|c|c|c|c|c|c|c|}
\hline Regressors & B & Std. error & $\beta$ & $\mathrm{T}$ & $\mathrm{p}$ & $\mathrm{R}^{2}$ \\
\hline Unschooled (N=29) & & & & & & 0.47 \\
\hline Constant & 15.52 & 3.67 & & 4.23 & 0.000 & \\
\hline Age (years) & -0.11 & 0.05 & -0.33 & -2.24 & 0.034 & \\
\hline PSS & 0.06 & 0.03 & 0.31 & 1.94 & 0.063 & \\
\hline GDS & -0.21 & 0.06 & -0.60 & -3.72 & 0.001 & \\
\hline Schooled $(\mathrm{N}=49)$ & & & & & & 0.08 \\
\hline Constant & 7.93 & 2.93 & & 2.70 & 0.010 & \\
\hline Age (years) & -0.02 & 0.04 & -0.07 & -0.46 & 0.651 & \\
\hline PSS & -0.02 & 0.03 & -0.13 & -0.81 & 0.421 & \\
\hline GDS & -0.04 & 0.06 & -0.18 & -1.12 & 0.267 & \\
\hline
\end{tabular}

EVLT: Elderly Verbal Learning Test, B: regression coefficients, Std. error: standard error of regression coefficient, $\beta$ : standardized regression coefficient, PSS: perceived stress scale, GDS: geriatric depression scale

Table 5. Group differences in multiple regression model on the EVLT Recognition

\begin{tabular}{|c|c|c|c|c|c|c|}
\hline Regressors & B & Std. error & $\beta$ & $\mathrm{T}$ & $\mathrm{p}$ & $\mathrm{R}^{2}$ \\
\hline Unschooled $(\mathrm{N}=29)$ & & & & & & 0.28 \\
\hline Constant & 38.12 & 6.90 & & 5.56 & 0.000 & \\
\hline Age (years) & -0.12 & 0.09 & -0.24 & -1.39 & 0.178 & \\
\hline PSS & 0.04 & 0.06 & 0.12 & 0.65 & 0.525 & \\
\hline GDS & -0.28 & 0.11 & -0.48 & -2.57 & 0.017 & \\
\hline Schooled $(\mathrm{N}=49)$ & & & & & & 0.21 \\
\hline Constant & 35.01 & 5.15 & & & 0.000 & \\
\hline Age (years) & -0.08 & 0.07 & -0.15 & -1.15 & 0.256 & \\
\hline PSS & -0.08 & 0.05 & -0.25 & -1.65 & 0.106 & \\
\hline GDS & -0.10 & 0.06 & -0.26 & -1.74 & 0.089 & \\
\hline
\end{tabular}

EVLT: Elderly Verbal Learning Test, B: regression coefficients, Std. error: standard error of regression coefficient, $\beta$ : standardized regression coefficient, PSS: perceived stress scale, GDS: geriatric depression scale

$(\mathrm{p}>0.089)$.

\section{DISCUSSION}

This study investigated education as a protective factor moderating the effect of depressive mood on memory impairment in normal elderly people. There were two main findings: 1) an increase in depressive mood resulted in significantly lower verbal memory performance for long-term recall and recognition memory, but not for short-term recall memory in the entire sample of 78 elderly participants, and 2) depressive mood significantly predicted verbal memory performance for short-term recall, long-term recall, and recognition memory in elderly individuals with less than 6 years of formal education, while it was not a predictor of the verbal memory performance among those who have completed or received more than primary education.

This study revealed that an increased level of depressive mood was associated with memory decline, which is parallel to previous reports regarding memory deficits among depressed individuals. ${ }^{51-53}$ It was found that late-life depression was associated with a 2 to 5 -fold increase in the risk of dementia, of which memory impairment is a highlighting characteristic. ${ }^{11,12}$ Neuroimaging studies involving hippocampal structure have time and time again offered informative findings for this area of research, since the hippocampus is involved in both memory performance and mood disorders. MRI studies evaluating hippocampus in late-life depression have indicated that older depressed patients have decreased hippocampal volumes compared to non-depressed individuals. ${ }^{54-57}$ Sheline and colleagues claimed that recurrent depression and longer duration of depressive episodes have been associated with hippocampal volume reduction. ${ }^{58-60}$ Others have examined hippocampal volume in late-life depression and subsequent cognitive decline. ${ }^{61}$ Hence, hippocampal morphology in depressive mood and memory function may play a role in the associative link between the two.

From the cognitive reserve literature, it can be hypothesized that individuals with higher reserve would be more successful at coping with the same amount of brain pathology, which may be accelerated by depressive mood. In this study, we investigated whether the association between depressive 
mood and memory impairment are moderated by individual difference in cognitive reserve. The results found education as a protective factor against the deleterious effects of depressive mood on memory in elderly women, which is one of the first findings regarding cognitive reserve moderating the effects of depression on memory. It further supports Le Carret and colleagues' claim that education is the most important factor in reducing cognitive decline. ${ }^{22}$

Overall the findings are consistent with the abundance of studies claiming that education reduces the risk of cognitive decline. ${ }^{30-34}$ In line with the cognitive reserve hypothesis, results from a number of studies suggest that an enriched environment may promote brain development or sustainability since it keeps the brain active and neurons constantly stimulated. ${ }^{62,63}$ This reserve allows individuals greater neural efficiency, greater neural capacity, and the ability for compensation, and in turn, alters the rate of cognitive decline in elderly people. The concept of cognitive reserve implies that receiving sufficient education and engaging in cognitive activity result in acquiring a higher level of cognitive reserve. It is important to keep in mind that higher cognitive reserve delays the onset of clinical presentation rather than truly decreasing dementia pathology. Yet, from a public health perspective, a delay of 5 years could potentially halve the prevalence of the disease, ${ }^{26}$ and in turn, lead to significant personal, social, and economic benefits. Furthermore, targeting cognitive reserve for interventions provides the advantage of having minimal potential for harm, as opposed to using drug treatments. It could also increase the general quality of life for elderly people by encouraging social engagement and more activity.

This study has several limitations. First, the participants were limited to only women due to significant difference in educational attainment between the two genders in Korea. Korean society had a tradition of prohibiting female education in public domain until mandatory education was introduced in 1948. Further, socioeconomic hardship due to colonization and wars during the first half of the 20th century made it difficult for girls to get education, and resulted in significant discrepancy in formal educational attainment between the genders. Hence, this high correlation between education and gender made it difficult to include both genders in this study. We controlled this correlation by including only elderly women in the study, but at the cost of representing only half of the population. Another limitation of the study is that since assessment of the level of depressive mood and cognitive performance was not done at the same time, the issue of temporal relationship between the two variables remains uncertain and requires further investigation. Finally, only educational attainment in early life was used as a proxy of cognitive reserve. In future studies, it would be desirable to measure a more comprehensive index of cognitive reserve by taking into account the quality of mental activity during the adult life, since this factor could vary greatly between individuals. An individual may have received little formal education but continued to engage in mentally stimulating activities throughout life, in which case her cognitive reserve could still be high.

In conclusion, the present study provides one of the first findings regarding cognitive reserve as a protective factor against the effects of depressive mood on memory impairment. Multiple factors may affect brain development and aging; some of them act as accelerators of age-related declines, and others play a moderating role, slowing age-related deterioration and delaying its advancement to clinical manifestation. This has important implications for developing potential interventions for the prevention of dementia.

\section{Acknowledgments}

This work was supported by the Seoul National University Research Grant.

\section{REFERENCES}

1. Depp CA, Harmell A, Vahia IV. Successful cognitive aging. In: Behavioral Neurobiology of Aging. Berlin Heidelberg: Springer, 2011, p.35-50.

2. Hedden T, Gabrieli JD. Insights into the ageing mind: a view from cognitive neuroscience. Nat Rev Neurosci 2004;5:87-96.

3. Light LL. Memory and aging: four hypotheses in search of data. Annu Rev Psychol 1991;42:333-376.

4. Grady CL, Craik FI. Changes in memory processing with age. Curr Opin Neurobiol 2000;10:224-231.

5. Park JH, Kim KW, Kim MH, Kim MD, Kim BJ, Kim SK, et al. A nationwide survey on the prevalence and risk factors of late life depression in South Korea. J Affect Disord 2012;138:34-40.

6. Park JH, Lee JJ, Lee SB, Huh Y, Choi EA, Youn JC, et al. Prevalence of major depressive disorder and minor depressive disorder in an elderly Korean population: results from the Korean Longitudinal Study on Health and Aging (KLoSHA). J Affect Disord 2010;125:234-240.

7. APA. Diagnostic and Statistical Manual of Mental Disorders (5th Ed., DSM-5). Washington, DC: American Psychiatric Press; 2013.

8. Beekman A, Deeg D, Braam A, Smit J, Van Tilburg W. Consequences of major and minor depression in later life: a study of disability, wellbeing and service utilization. Psychol Med 1997;27:1397-1409.

9. Cohen RM, Weingartner H, Smallberg SA, Pickar D, Murphy DL. Effort and cognition in depression. Arch Gen Psychiatry 1982;39:593-597.

10. Sternberg DE, Jarvik ME. Memory functions in depression. Arch Gen Psychiatry 1976;33:219-224.

11. Saczynski JS, Beiser A, Seshadri S, Auerbach S, Wolf P, Au R. Depressive symptoms and risk of dementia The Framingham Heart Study. Neurology 2010;75:35-41.

12. Andersen K, Lolk A, Kragh-Sørensen P, Petersen NE, Green A. Depression and the risk of Alzheimer disease. Epidemiology 2005;16:233-238.

13. Gatz JL, Tyas SL, John PS, Montgomery P. Do depressive symptoms predict Alzheimer's disease and dementia? J Gerontol A Biol Sci Med Sci 2005;60:744-747.

14. Chen R, Hu Z, Wei L, Qin X, McCracken C, Copeland JR. Severity of depression and risk for subsequent dementia: cohort studies in China and the UK. Br J Psychiatry 2008;193:373-377.

15. Wilson RS, Barnes LL, Mendes de Leon CF, Aggarwal NT, Schneider JS, Bach J, et al. Depressive symptoms, cognitive decline, and risk of AD in older persons. Neurology 2002;59:364-370.

16. Becker JT, Chang YF, Lopez OL, Dew MA, Sweet RA, Barnes D, et al. 
Depressed mood is not a risk factor for incident dementia in a community-based cohort. Am J Geriatr Psychiatry 2009;17:653-663.

17. Lindsay J, Laurin D, Verreault R, Hébert R, Helliwell B, Hill GB, et al. Risk factors for Alzheimer's disease: a prospective analysis from the Canadian Study of Health and Aging. Am J Epidemiol 2002;156:445-453.

18. Scarmeas N, Stern Y. Cognitive reserve: implications for diagnosis and prevention of Alzheimer's disease. Curr Neurol Neurosci Rep 2004;4: 374-380.

19. Stern Y, Alexander GE, Prohovnik I, Mayeux R. Inverse relationship between education and parietotemporal perfusion deficit in Alzheimer's disease. Ann Neurol 1992;32:371-375.

20. Tucker M, A Stern Y. Cognitive reserve in aging. Curr Alzheimer Res 2011;8:354-360.

21. Stern Y. Cognitive reserve. Neuropsychologia 2009;47:2015-2028.

22. Le Carret N, Lafont S, Mayo W, Fabrigoule C. The effect of education on cognitive performances and its implication for the constitution of the cognitive reserve. Dev Neuropsychol 2003;23:317-337.

23. Brayne C, Calloway P. The association of education and socioeconomic status with the Mini Mental State Examination and the clinical diagnosis of dementia in elderly people. Age Ageing 1990;19:91-96.

24. Evans DA, Hebert LE, Beckett LA, Scherr PA, Albert MS, Chown MJ, et al. Education and other measures of socioeconomic status and risk of incident Alzheimer disease in a defined population of older persons. Arch Neurol 1997;54:1399-1405.

25. Fratiglioni L, Grut M, Forsell Y, Viitanen M, Grafström M, Holmen K, et al. Prevalence of Alzheimer's disease and other dementias in an elderly urban population Relationship with age, sex, and education. Neurology 1991;41:1886-1892.

26. Katzman R. Education and the prevalence of dementia and Alzheimer's disease. Neurology 1993;43:13-20.

27. Mortel KF, Meyer JS, Herod B, Thornby J. Education and occupation as risk factors for dementias of the Alzheimer and ischemic vascular types. Dementia 1995;6:55-62.

28. Stern Y, Gurland B, Tatemichi TK, Tang MX, Wilder D, Mayeux R. Influence of education and occupation on the incidence of Alzheimer's disease. JAMA 1994;271:1004-1010.

29. Hall C, Derby C, LeValley A, Katz M, Verghese J, Lipton R. Education delays accelerated decline on a memory test in persons who develop dementia. Neurology 2007;69:1657-1664.

30. Blum JE, Jarvik LF. Intellectual performance of octogenarians as a function of education and initial ability. Hum Dev 1974;17:364-375.

31. Colsher PL, Wallace RB. Longitudinal application of cognitive function measures in a defined population of community-dwelling elders. Ann Epidemiol 1991;1:215-230.

32. Evans DA, Beckett LA, Albert MS, Hebert LE, Scherr PA, Funkenstein $\mathrm{HH}$, et al. Level of education and change in cognitive function in a community population of older persons. Ann Epidemiol 1993;3:71-77.

33. Snowdon DA, Kemper SJ, Mortimer JA, Greiner LH, Wekstein DR, Markesbery WR. Linguistic ability in early life and cognitive function and Alzheimer's disease in late life. Findings from the Nun Study. JAMA 1996;275:528-532.

34. Schmand B, Smit J, Geerlings M Lindeboom J. The effects of intelligence and education on the development of dementia. A test of the brain reserve hypothesis. Psychol Med 1997;27:1337-1344.

35. Albert MS, Jones K, Savage CR, Berkman L, Seeman T, Blazer D, et al. Predictors of cognitive change in older persons: MacArthur studies of successful aging. Psychol Aging 1995;10:578.

36. Bosma H, Van Boxtel M, Ponds R, Houx P, Jolles J. Education and agerelated cognitive decline: the contribution of mental workload. Educ Gerontol 2003;29:165-173

37. Butler SM, Ashford JW, Snowdon DA. Age, education, and changes in the Mini-Mental State Exam scores of older women: Findings from the Nun Study. J Am Geriatr Soc 1996;44:675-681.

38. Farmer ME, Kittner SJ, Rae DS, Bartko JJ, Regier DA. Education and change in cognitive function: the epidemiologic catchment area study. Ann Epidemiol 1995;5:1-7.
39. Lyketsos CG, Chen LS, Anthony JC. Cognitive decline in adulthood: an 11.5-year follow-up of the Baltimore Epidemiologic Catchment Area study. Am J Psychiatry 1999;156:58-65.

40. Stern Y. What is cognitive reserve? Theory and research application of the reserve concept. J Int Neuropsychol Soc 2002;8:448-460.

41. Chey J. Korean Dementia Rating Scale-2. Seoul: Hakjisa; 2011.

42. Chey J, Lee SA. Development of the Norms for the Korean-Dementia Rating Scale. Korean J Clin Psychol 1997;11:423-433.

43. Yesavage JA, Brink TL, Rose TL, Lum O, Huang V, Adey M, et al. Development and validation of a geriatric depression screening scale: a preliminary report. J Psychiatr Res 1983;17:37-49.

44. Montorio I, Izal M. The Geriatric Depression Scale: a review of its development and utility. Int Psychogeriatr 1996;8:103-112.

45. Zarit SH, Eiler J, Hassinger M. Clinical Assessment. In: Birren JE, Schaie KW, Editors. Handbood of the Psychology of Aging. New York: Van Nostrand-Reinhold, 1985. p.725-754.

46. Cohen S, Kamarck T, Mermelstein R. A global measure of perceived stress. J Health Soc Behav 1983:385-396.

47. Baek YM. Korean Version of the Perceived Stress Scale-10: Development of the Scale and Exploring the Effects of Perceied Stress on Memory. Seoul: Department of Psychology. Seoul National University; 2010.

48. Chey J. Elderly Memory Disorder Scale. Seoul: Hakjisa; 2007.

49. Chey J, Lee J, Kim M, Kim H. Development and standarization of the Elderly Verbal Learning Test (EVLT). Korean J Psychol Gen 2006;3: 141-173.

50. Delis DC, Kramer JH, Kaplan E, Thompkins BAO. CVLT: California Verbal Learning Test-Adult Version: Manual. San Antonio, TX: Psychological Corporation; 1987.

51. Fossati P, Coyette F, Ergis AM, Allilaire JF. Influence of age and executive functioning on verbal memory of inpatients with depression. J Affect Disord 2002; 68: 261-271.

52. Ilsley J, Moffoot AP, O'Carroll R. An analysis of memory dysfunction in major depression. J Affect Disord 1995;35:1-9.

53. Burt DB, Zembar MJ, Niederehe G. Depression and memory impairment: a meta-analysis of the association, its pattern, and specificity. Psychol Bull 1995;117:285-305.

54. Steffens DC, Byrum CE, McQuoid DR, Greenberg DL, Payne ME, Blitchington TF, et al. Hippocampal volume in geriatric depression. Biol Psychiatry 2000;48:301-309.

55. Bell-McGinty S, Butters MA, Meltzer CC, Greer PJ, Reynolds III CF, Becker JT. Brain morphometric abnormalities in geriatric depression: long-term neurobiological effects of illness duration. Am J Psychiatry 2002;159:1424-1427.

56. Lloyd AJ, Ferrier IN, Barber R, Gholkar A, Young AH, O'brien JT. Hippocampal volume change in depression: late-and early-onset illness compared. Br J Psychiatry 2004;184:488-495.

57. Hickie I, Naismith S, Ward PB, Turner K, Scott E, Mitchell P, et al. Reduced hippocampal volumes and memory loss in patients with earlyand late-onset depression. Br J Psychiatry 2005;186:197-202.

58. Sheline YI, Wang PW, Gado MH, Csernansky JG, Vannier MW. Hippocampal atrophy in recurrent major depression. Proc Natl Acad Sci 1996;93:3908-3913.

59. Sheline YI, Gado MH, Kraemer HC. Untreated depression and hippocampal volume loss. Am J Psychiatry 2003;160:1516-1518.

60. Sheline YI, Sanghavi M, Mintun MA, Gado MH. Depression duration but not age predicts hippocampal volume loss in medically healthy women with recurrent major depression. J Neurosci 1999;19:5034-5043.

61. O’Brien JT, Lloyd A, McKeith I, Gholkar A, Ferrier N. A longitudinal study of hippocampal volume, cortisol levels, and cognition in older depressed subjects. Am J Psychiatry 2004;161:2081-2090.

62. Swaab DF. Brain aging and Alzheimer's disease, "wear and tear" versus "use it or lose it". Neurobiol Aging 1991;12:317-324.

63. Valenzuela MJ, Sachdev P, Wen W, Chen X, Brodaty H. Lifespan mental activity predicts diminished rate of hippocampal atrophy. PLoS One 2008; $3: \mathrm{e} 2598$. 